\title{
Temática indígena no livro de história a partir da vigência da BNCC
}

\author{
Indigenous thematic in the history book from the effectiveness of the BNCC
}

\author{
Paulo Cézar Camurça Melo \\ Mestre em História e Letras \\ Universidade Estadual do Ceará - UECE. \\ Quixadá, Ceará - Brasil. \\ paulocezar.c.melo@hotmail.com \\ Fátima Maria Leitão Araújo \\ Doutora em Educação \\ Universidade Estadual do Ceará - UECE. \\ Fortaleza, Ceará - Brasil. \\ fatima.leitao@uece.br \\ (iD) Joilson Silva de Sousa \\ Doutorando em Educação \\ Universidade Federal do Rio Grande do Norte - UFRN. \\ Natal, Rio Grande do Norte - Brasil. \\ joilsondesousa@hotmail.com
}

Resumo: O livro didático é uma das principais ferramentas utilizadas pelo professor e, muitas vezes, a única fonte de leitura e pesquisa para grande parte dos estudantes da Educação Básica. Assim sendo, o escopo do texto é refletir sobre a contribuição do Programa Nacional do Livro Didático - PNLD e do ensino de História como componente curricular para a qualidade da Educação Básica. A análise privilegiou livros didáticos de história com conteúdos relacionados à Temática Indígena nos Anos Finais do Ensino Fundamental. Concluímos que o livro didático é um instrumento multifacetado, pois carrega interesses do mercado, discursos controlados pelas gestões estatais de cada época e ao mesmo tempo um instrumento com diversas possibilidades metodológicas que contribui para o trabalho docente. Finalmente, entendemos o PNLD como programa fundamental para o acesso universal ao livro didático e a qualidade do ensino público na Educação Básica.

Palavras chave: livro didático; políticas educacionais; temática indígena

Abstract: The textbook is one of the main tools used by the teacher and, often, the only source of reading and research for most students of Basic Education. Therefore, the scope of the text is to reflect on the contribution of the National Textbook Program - PNLD and the teaching of History as a curricular component for the quality of Basic Education. The analysis favored history textbooks with content related to Indigenous Theme in the Final Years of Elementary School. We conclude that the textbook is a multifaceted instrument, as it carries market interests, speeches controlled by the state administrations of each era and, at the same time, an instrument with several methodological possibilities that contributes to the teaching work. Finally, we understand PNLD as a fundamental program for universal access to textbooks and the quality of public education in Basic Education.

Keywords: textbook; educational policies; indigenous thematic.

Cite como

(ABNT NBR 6023:2018)

MELO, Paulo Cézar Camurça; ARAÚJO, Fátima Maria Leitão; SOUSA, Joilson Silva. Temática indígena no livro de história a partir da vigência da BNCC. Dialogia, São Paulo, n. 40, p. 1-18, e19986, jan./abr. 2022. Disponível em: https://doi.org/10.5585/40.2022.19986.

American Psychological Association (APA)

Melo, P. C. C., Araújo, F. M. L., \& Sousa, J. S. (2022, jan./abr.) Temática indígena no livro de história a partir da vigência da BNCC. Dialogia, São Paulo, 40, p. 1-18, e19986. https://doi.org/10.5585/40.2022.19986. 


\section{Introdução}

O livro didático é um dos recursos pedagógicos mais utilizados atualmente em toda a Educação Básica. Não só é a principal fonte de leitura de grande parte dos estudantes das escolas públicas, mas também, constitui ferramenta para o professor, facilitando o planejamento do conteúdo e das atividades a serem trabalhadas nas aulas e contribuindo com sugestões de uso de outros recursos, como filmes e sites. Diante de sua enorme utilização nas escolas, muitos são os estudos acadêmicos relacionados a esse recurso pedagógico, de modo geral e em disciplinas específicas.

$\mathrm{Na}$ área da História, há várias pesquisas sobre esse instrumento que está presente em todas as escolas públicas do Brasil por meio do Programa Nacional do Livro Didático - PNLD, que avalia, compra e distribui para todos os estudantes dessas instituições. Silva (2014), analisou o processo de escolha dos livros didáticos e sua utilização no cotidiano escolar. De acordo com a autora, o livro didático é um dos recursos mais usados no processo de ensino aprendizado, embora, em muitas escolas, ele ainda seja subutilizado, ou seja, o professor não aproveita todas as possibilidades pedagógicas disponíveis no livro, como textos complementares, atividades, imagens, dicas de filmes, sites etc. (SILVA, 2014).

De acordo com Silva, Magalhães do Ó e Pimentel (2015), no decorrer do século XX as pesquisas no Brasil sobre o livro didático se deram em três blocos: o primeiro, sobre a ideologia contida no material; o segundo, sobre o conteúdo e o terceiro, sobre os usos desse instrumento no cotidiano escolar.

Assim como o livro didático, o ensino de história e cultura dos povos indígenas e dos afrobrasileiros, no que diz respeito à Lei n. 11.645/2008, vem sendo objeto de pesquisas nos últimos anos no Brasil. Conforme esclarecem Nascimento, Silva e Ávila (2015), primeiro tivemos a Lei n. 10.639 de 2003 que institui a obrigatoriedade da História e da Cultura afro-brasileiras como conteúdo escolar, acrescentando dois artigos à Lei de Diretrizes e Bases da Educação Nacional LDBEN. Estabelecendo, assim, o ensino de história e cultura afro-brasileira através de temas, como a história da África e dos africanos, a luta dos negros no Brasil, a cultura negra brasileira e o negro na formação da sociedade nacional. Em 2008, a Lei n. 11.645 foi sancionada, alterando novamente a LDBEN para incluir também a obrigatoriedade do ensino de história e cultura dos povos indígenas.

Recentemente, uma agressiva política neoliberal tem sido imposta no país, a partir da posse do Presidente Michel Temer, que assumiu a presidência da república após o impedimento da então Presidente Dilma Rousseff. Apresentando um programa de governo totalmente contrário aos 
apresentados pelo partido que elegeu a Presidente impedida. Assim, os interesses do mercado voltam a prevalecer e as conquistas sociais começam a ser implodidas em uma velocidade assustadora. As garras do capital em todas as áreas, inclusive na educação, aceleram os projetos privatistas e as mudanças indicadas pelas organizações que visam à ampliação dos projetos do ensino privado e voltados para formar cidadãos acríticos, sustentadores da estrutura do império das transnacionais. Assim, de forma repentina e autoritária, em um contexto neoliberal, é concluída a reforma do ensino médio e implantada a Base Nacional Comum Curricular - BNCC.

Barbosa (2015, on-line apud VEIGA, 2015, on-line), afirma que a BNCC, da forma que foi elaborada, compromete não só a autonomia docente, mas também “o direito à diferença e o respeito aos saberes e culturas locais por meio dos padrões impostos e do controle externo dos processos pedagógicos". Para Cássio (2018), a BNCC é um retrocesso na educação, seu projeto centralizador é uma ameaça concreta a projetos educacionais democráticos, e a propaganda que a associa a uma suposta igualdade de oportunidades revela a intenção de persuadir as pessoas daquilo que a Base efetivamente não pode fazer. Barbosa (2015, on-line apud VEIGA, 2015, on-line), acrescenta que a unificação dos currículos nacionais serve para impor conteúdos "baseados no pensamento e no modelo econômico hegemônicos", [...] para coibir o trabalho autônomo, criativo e respeitoso da riqueza das diferenças sociais, culturais e de aprendizagem que caracterizam os cotidianos das escolas e aquilo que neles se passa.

No presente artigo, desenvolvemos um estudo empírico no e sobre o livro didático de História, tendo por foco a análise das abordagens sobre os povos indígenas em duas edições da coleção: História Sociedade \& Cidadania. $3^{\mathrm{a}}$ edição - 2015 e $4^{\mathrm{a}}$ edição - 2018, na tentativa de responder a seguinte pergunta: Como é tratada a Temática Indígena nos Livros Didáticos de História do Ensino Fundamental?

Para tanto, analisamos uma edição de antes e outra posterior à publicação da BNCC. Com tal análise pretendemos identificar mudanças e/ou permanências na visão sobre os povos indígenas, em livros adotados nos 6..$^{\circ}$ e 7. ${ }^{\circ}$ ano dos Anos Finais do Ensino Fundamental.

\section{A coleção "história sociedade e cidadania” - mudanças e permanências (2015-2020)}

De acordo com o Guia do PNLD 2017, a coleção História Sociedade e Cidadania, $3^{\text {a }}$ edição - 2015, deu uma atenção especial ao tratamento da história e cultura dos povos indígenas, favorecendo o trabalho do professor na construção de uma sociedade mais tolerante. Ainda segundo os avaliadores, os livros desta coletânea mostram a participação dessas sociedades como agentes da história, dando-lhes visibilidade nos vários lugares, e em diferentes tempos históricos. 
Para a quarta edição dessa obra, impressa em 2018, os avaliadores do PNLD 2020 tiveram também uma visão positiva em relação abordagem da temática indígena. Para os avaliadores, há abordagens, imagens e atividades que promovem a cultura e a história dessas sociedades, principalmente nos volumes dos $6 .^{\circ}$ e $7 .^{\circ}$ ano, em que há passagens colocando em destaque personagens históricos pertencentes a essas etnias.

Dessa forma, iniciamos nossa análise a partir do livro do $6^{\circ}{ }^{\circ}$ ano, da referida coleção, pela edição mais recente, que atende as determinações da BNCC, para depois estabelecermos uma comparação com a edição de 2015. Conforme veremos mais adiante, identificaremos a temática indígena presente nos capítulos, apresentadas primeiramente em tabelas que descrevem o conteúdo da obra e em seguida passamos a mostrar o mesmo tema na edição anterior.

\subsection{O Livro Didático de História do $6^{\circ}$ Ano - Volume 1}

Atendendo aos critérios da BNCC, o livro do $6^{\circ}$ ano, da coleção História Sociedade \& Cidadania apresenta a divisão da unidade I em 4 capítulos. Cada um dos títulos desses capítulos está relacionado a um objeto de conhecimento determinado pela BNCC, conforme o quadro Conteúdos, objetos do conhecimento e habilidades, presente no manual do professor, cujo recorte está na tabela a seguir.

Tabela 1 - Conteúdos, objetos do conhecimento e habilidades da unidade I

\begin{tabular}{|c|c|c|}
\hline Capítulos & Objetos de Conhecimento & $\begin{array}{r}\text { Habilidades } \\
\end{array}$ \\
\hline \multirow{2}{*}{ História e tempo } & $\begin{array}{l}\text { A questão do tempo, sincronias e } \\
\text { diacronias: reflexões sobre o } \\
\text { sentido das cronologias }\end{array}$ & $\begin{array}{l}\text { (EF06HI01) Identificar diferentes formas } \\
\text { de compreensão da noção de tempo e de } \\
\text { periodização dos processos históricos } \\
\text { (continuidades e rupturas). }\end{array}$ \\
\hline & \multicolumn{2}{|c|}{$\begin{array}{l}\text { Conteúdos: O estudo da História; Tempo; O tempo histórico; Calendários; } \\
\text { Linha do tempo; Calendário cristão; Calendário do povo Kayabi; A divisão do } \\
\text { tempo histórico em períodos. }\end{array}$} \\
\hline \multirow{2}{*}{$\begin{array}{l}\text { Fontes e conhecimento } \\
\text { sem História }\end{array}$} & $\begin{array}{l}\text { Formas de registro da história e } \\
\text { da produção do conhecimento } \\
\text { histórico }\end{array}$ & $\begin{array}{l}\text { (EF06HI02) Identificar a gênese da } \\
\text { produção do saber histórico }\end{array}$ \\
\hline & \multicolumn{2}{|c|}{$\begin{array}{l}\text { Conteúdos: As fontes da História; O conhecimento histórico; A colaboração de } \\
\text { outros profissionais para o conhecimento histórico; Sujeitos históricos. }\end{array}$} \\
\hline \multirow{2}{*}{$\begin{array}{l}\text { Os primeiros } \\
\text { povoadores da Terra }\end{array}$} & $\begin{array}{l}\text { As origens da humanidade, seus } \\
\text { deslocamentos e os processos de } \\
\text { sedentarização }\end{array}$ & $\begin{array}{l}\text { (EF06HI03) Identificar as hipóteses } \\
\text { científicas sobre o surgimento da espécie } \\
\text { humana e sua historicidade e analisar os } \\
\text { significados dos mitos de fundação. }\end{array}$ \\
\hline & \multicolumn{2}{|c|}{$\begin{array}{l}\text { Conteúdos: A origem do ser humano; O criacionismo; Mito iorubá de criação } \\
\text { do mundo; O evolucionismo; Os primeiros hominídeos; Fósseis; O Homo } \\
\text { sapiens sapiens; Caçadores e coletores; O domínio do fogo; Agricultores e } \\
\text { pastores; Idade dos metais; Pintura rupestre. }\end{array}$} \\
\hline
\end{tabular}




\begin{tabular}{|c|c|c|}
\hline Capítulos & Objetos de Conhecimento & Habilidades \\
\hline \multirow[t]{2}{*}{$\begin{array}{c}\text { Primeiros habitantes da } \\
\text { América }\end{array}$} & $\begin{array}{l}\text { As origens da humanidade, seus } \\
\text { deslocamentos e os processos de } \\
\text { sedentarização }\end{array}$ & $\begin{array}{l}\text { (EF06HI04) Conhecer as teorias sobre a } \\
\text { origem do homem americano. } \\
\text { (EF06HI05) Descrever modificações da } \\
\text { natureza e da paisagem realizadas por } \\
\text { diferentes tipos de sociedade, com } \\
\text { destaque para os povos indígenas } \\
\text { originários e povos africanos, e discutir a } \\
\text { natureza e a lógica das transformações } \\
\text { ocorridas. } \\
\text { (EF06HI06) Identificar geograficamente } \\
\text { as rotas de povoamento no território } \\
\text { americano. }\end{array}$ \\
\hline & \multicolumn{2}{|c|}{$\begin{array}{l}\text { Conteúdos: Da África para outros continentes; Migração para o continente } \\
\text { americano; Descobertas sobre a presença humana na América; Os estudos de } \\
\text { Walter Neves e Niède Guidon; Parque Nacional da Serra da Capivara; } \\
\text { Habitantes das terras americanas; Grandes mamíferos; Caçadores e coletores; } \\
\text { O povo de Lagoa Santa; O povo de Umbu; Os povos dos sambaquis; } \\
\text { Agricultores da Amazônia. }\end{array}$} \\
\hline
\end{tabular}

Fonte: Elaborado a partir de Boulos, 2018, v.1.

Podemos ainda observar no quadro que cada habilidade da BNCC está relacionada a cada objeto de conhecimento e, consequentemente, a cada capítulo. Além disso, a subdivisão destes capítulos em diversos conteúdos programáticos. Estes não são determinados pela BNCC, e sim, subtítulos de cada capítulo elaborados pelo autor, assim como os próprios títulos. Porém, nessa coletânea, observamos que essa nomeação dos capítulos é bem afinada com aquela definida pela BNCC para cada objeto de conhecimento, quase como um resumo ou uma redução no número de palavras utilizadas.

Assim sendo, para iniciar nossa análise da representação indígena nessa coleção, começamos por identificar a temática indígenas explícitas nas habilidades apontadas para cada capítulo e/ou nos objetos de conhecimento de cada um deles. $\mathrm{Na}$ sequência, procuramos identificar esses mesmos temas nos volumes da edição anterior da coletânea, pois, com a mudança para atender a BNCC, alguns conteúdos passaram a ser abordados, nos novos livros, em séries do ensino fundamental - anos finais, diferentes daquelas anteriormente pertencentes.

Ao fazer uma leitura das habilidades ligadas à unidade I, encontramos, de imediato, aquela que está mais explícita sua referência a estudo da história e cultura dos povos indígenas, EF06HI05 - "Descrever modificações da natureza e da paisagem realizadas por diferentes tipos de sociedade, com destaque para os povos indígenas originários e povos africanos, e discutir a natureza e a lógica das transformações ocorridas” (BRASIL, 2017, p.417). É mais explícita principalmente na parte que ela determina "destaque para os povos indígenas originários".

Por essa razão, a análise da representação indígena nesse capítulo, que além da habilidade EF06HI05, segundo Boulos (2015) atende a outras duas, EF06HI04 - "conhecer as teorias sobre 
a origem do homem americano", e EF06HI06 - "Identificar geograficamente as rotas de povoamento no território americano" (BRASIL, 2017, p.417).

Nesse sentido, o capítulo aborda as teorias científicas que tentam responder de onde, quando e como chegou os primeiros seres humanos nesse continente, um tema fascinante, que traz estudos da Antropologia e da História. As primeiras referências a nomes de povos dos continentes são daqueles que deixaram apenas fontes arqueológicas, "entre eles estavam o povo de Lagoa Santa, o povo de Umbu (também conhecido como povo da flecha) e os povos dos sambaquis", povos coletores e caçadores (BOULOS, 2018, p.59). Porém, é no tópico “Agricultores da Amazônia” que a cultura dos povos que deixaram seus descendentes indígenas, no Brasil, é mais visibilizada. Informa o texto principal que,

\begin{abstract}
Segundo a arqueóloga Anna Roosevelt, os povos da região amazônica começaram a praticar a agricultura há cerca de 7 mil anos. Eles desenvolveram cultivos próprios, como plantas medicinais e corantes; mas a descoberta mais importante desses grupos foi o cultivo da mandioca, raiz de alto valor nutritivo com algumas variedades venenosas. Os agricultores da Amazônia descobriram que ralando, prensando e torrando essas espécies de mandioca conseguiam extrair o veneno que elas continham. Eles produziam alimentos como a farinha, o beiju e a tapioca (BOULOS, 2018, p. 62).
\end{abstract}

Na mesma página mostra uma foto recente, 2011, de uma moça kalapalo ralando mandioca no Parque Indígena do Xingu - MT. A imagem apresenta algo que até o momento, nos tópicos anteriores do capítulo, não era abordado, ou seja, os povos indígenas no tempo presente. Além disso, mostra a presença dessa cultura nos costumes alimentares de grande parte do povo brasileiro, o consumo de alimentos preparados a partir da mandioca, um produto agrícola dos povos indígenas e que necessita de uma tecnologia descoberta por eles para extrair o veneno da planta para que ela seja usada.

É neste tópico que consideramos que foi dada uma maior visibilidade a temática indígena no capítulo. Embora seja importante conhecer sobre a chegada dos povos indígenas nesse continente, em um passado distante, através de contribuições de diversas ciências, a história e cultura dos diversos povos indígenas atuais torna-se mais relevante para que essas sociedades, tenham direito a história e culturas próprias, para superar preconceitos e violências vindas da sociedade ocidental, capitalista. Portanto, percebemos ser necessário ampliar essa visibilidade nos livros didáticos, para romper com a colonialidade do saber, que permaneceu nas terras da América, mesmo depois do colonialismo, conforme observou Aníbal Quijano (2005).

Encontramos no livro do $6 .^{\circ}$ ano, $3^{a}$ edição, um capítulo semelhante, porém, com outro título. Ou seja, o capítulo - Primeiro habitante da América, da $4^{a}$ edição, foi adaptado do capítulo 4 - A pré-história brasileira, da unidade 2 do livro do $6 .^{\circ}$ ano, da $3^{\text {a }}$ edição. Com exceção da página 
de abertura, as outras, que abordam os estudos científicos, arqueológicos sobre a origem dos povos mais antigos da América, são textos bastante semelhantes àqueles do livro $4^{a}$ edição.

Porém, encontramos uma diferença significativa justamente no tópico que, conforme explicitado anteriormente, consideramos o de maior importância para mostrar elementos culturais referentes aos povos indígenas atuais. Ou seja, quando analisamos o tópico - Agricultores da Amazônia, da edição da coleção publicada depois da BNCC, destacamos sua importante contribuição para a visibilidade dos povos indígenas atuais e sua cultura. Já analisando a edição anterior à $\mathrm{BNCC}$, encontramos esse tópico, com um texto bem mais amplo, intitulado: Agricultores e ceramistas da Amazônia.

Portanto, além de informar sobre a agricultura, plantas medicinais e o beneficiamento da mandioca como atividades realizadas pelos povos originários, o texto contempla mais duas páginas, informando sobre a produção de cerâmica iniciada nos povos indígenas no mesmo período que se inicia a atividade agrícola desses povos na Amazônia. Dessa forma, com texto e imagens de objetos e estatuetas de cerâmicas, o tópico presente na edição mais antiga é mais significativo para o ensino da cultura indígenas e sua contribuição na formação da cultura do povo brasileiro.

Identificada essa primeira mudança, passamos para a próxima comparação entre capítulos das duas edições. Usando a mesma metodologia, voltamos à unidade 1 da edição mais recente, direcionando à habilidade EF06H03 - "Identificar as hipóteses científicas sobre o surgimento da espécie humana e sua historicidade e analisar os significados dos mitos de fundação" (BRASIL, 2017, p. 417).

Encontramos o tema no livro do $6 .^{\circ}$ ano da edição de 2015 no capítulo 3 e com o mesmo título, os primeiros povoadores da Terra. Observa-se que é quase o mesmo texto e imagens da edição de 2018. Porém, na edição de 2015, no final do capítulo, na seção atividades, uma página inteira é dedicada a um texto de Kaka Werá Jecupé, “Um mito tupi-guarani”. Dessa forma, uma narrativa religiosa de um povo indígena, sobre a origem da vida, é colocada ao aluno nessa edição. Já na edição de 2018 este texto é substituído por outro que não é relacionado a temática indígena.

A próxima habilidade da BNCC usada para a comparação das edições foi a EF06HI01 "Identificar diferentes formas de compreensão da noção de tempo e de periodização dos processos históricos (continuidades e rupturas)" (BRASIL, 2017, p. 417).

Não podemos afirmar que essa frase, que determina a habilidade a ser desenvolvida, leva de imediato a temas relacionados a história e cultura dos povos indígenas, mas cabe lembrar que há sociedades com diferentes formas de periodizar os processos históricos e que as sociedades indígenas também têm seus próprios modos de perceber e medir o tempo. Todavia, a habilidade 
não especifica quais são essas sociedades. Assim, não exige que alguma temática indígena seja abordada. Portanto, ao elaborar um livro didático que contemple essa habilidade da BNCC, principalmente se não for um livro que, em edições anteriores, já venha incluindo os costumes dos indígenas quando trata do assunto tempo na história. Não é o caso do livro em análise.

Mas, vamos ao objeto de conhecimento da BNCC. De acordo com o documento dessa norma, a habilidade EF06HI01 é relacionada ao objeto de conhecimento "A questão do tempo, sincronias e diacronias: reflexões sobre o sentido das cronologias". Para esse título, vale o mesmo raciocínio, e está a uma distância ainda maior da explícita relação com a temática indígena.

No livro em análise, História Sociedade \& Cidadania, $4^{a}$ edição - 2018, esse tema é apresentado no capítulo 1 - História e tempo. Na página de abertura, o texto explica situações da vida cotidiana em que a percepção do tempo ocorre de modo diferente, dependendo da situação vivida pela mesma pessoa.

Após explicar o conceito de tempo na História, apontar o objeto de estudo dessa disciplina, o calendário cristão usado por ela para periodização, e mostrar os calendários do povo judeu e muçulmano, um tópico esclarece que $\mathrm{O}$ tempo histórico se relaciona às mudanças e permanências na trajetória dos seres humanos na Terra, portanto está relacionado à história da humanidade. Porém, adverte que:

\footnotetext{
[...] as mudanças não ocorrem do mesmo jeito e nem no mesmo ritmo em todo lugar; é que cada povo tem um tempo e um ritmo que lhe são próprios. [...] nem todos os habitantes do Brasil vivem do mesmo jeito e nem no mesmo ritmo. Os Kayabi (indígenas do Rio dos Peixes, no norte do Mato Grosso), por exemplo, vivem em um tempo histórico diferente do dos habitantes de cidades brasileiras. Observando o calendário dos Kayabi, percebe-se que eles organizam sua vida com base nos acontecimentos naturais, isto é, guiam-se pelo tempo da natureza (BOULOS, 2018, p. 14-15).
}

O autor, evidencia que cada sociedade tem sua história e modo de organizar seu tempo, dando exemplo do povo Kayabi. Na sequência do texto, são dedicadas duas páginas de imagens e legendas representando o calendário dessa etnia indígena.

$\mathrm{Na}$ edição anterior - 2015, os temas contemplados no capítulo - História e Tempo da edição de 2018, são divididos em dois capítulos: História e fontes históricas - capítulo 1; e Cultura, patrimônio e tempo - capítulo 2.

No capítulo 2, encontramos no tópico - Formas e instrumentos de medir o tempo, ao lado do texto principal, uma fotografia com pessoas do povo Kalapalo, abrindo pequi, em Querência MT. Um pequeno texto ao lado da imagem informa que "os Kalapalos são grupos humanos da atualidade que organiza suas atividades com base nos fenômenos da natureza. O tempo da colheita 
do pequi, por exemplo, que ocorre na estação chuvosa é o período de confraternização entre as diversas aldeias kalapalos” (BOULOS, 2015, p.32).

Ainda neste capítulo, o tópico com o mesmo nome, "o tempo histórico", com informações semelhantes e mesma referência ao povo Kayabi, presente na edição de 2018. Na seção Atividades, uma questão com fotografias mostrando hábitos culturais de indivíduos de três diferentes povos, entre elas, uma do cacique Raoni, líder do povo Kaiapó.

Voltamos a edição de 2018, no livro do 6. ${ }^{\circ}$ ano para, a partir da habilidade EF06HI02 Identificar a gênese da produção do saber histórico e analisar o significado das fontes que originaram determinadas formas de registro em sociedades e épocas distintas - fazer a leitura da temática indígena nos capítulos correspondentes.

Essa habilidade corresponde ao objeto de conhecimento "Formas de registro da história e da produção do conhecimento histórico". No capítulo 2 do livro do 6. a ano, edição 2018, ficou intitulado como: Fontes e conhecimentos em História.

No texto principal do capítulo nenhuma referência aos povos indígenas. Somente na seção Atividades: tópico I - Retomando, onde duas imagens de artesanato indígena são apresentadas para o aluno classificá-las como fontes escritas, visuais, orais ou materiais; e tópico III - Você cidadão! Em que consta um trecho de texto de Mariana Alvim, publicado pelo site da BBC News Brasil, sobre os mantos usados pelos tupinambás do século XVII, que estão em museus na Europa. A lado do texto, uma fotografia de um deles, após o texto questões sobre fontes históricas e sobre patrimônio nacional.

Os temas trados no capítulo 2 da edição de 2018 são encontrados no capítulo 1 - História e fonte históricas, da edição de 2015. No texto principal, também nenhuma referência aos indígenas, mas encontramos uma imagem atual com crianças indígenas brincando, após um texto que explica sobre a diferentes formas de fontes históricas.

Concluída a unidade 1 do livro do $6 .^{\circ}$ ano, passamos a unidade II, que apresenta a estrutura de capítulo e habilidades da BNCC de acordo com a tabela 2.

Tabela 2 - Conteúdos, objetos do conhecimento e habilidades da Unidade II

\begin{tabular}{|c|c|c|}
\hline Capítulos & Objetos de conhecimento & $\begin{array}{r}\text { Habilidades } \\
\end{array}$ \\
\hline \multirow[t]{2}{*}{$\begin{array}{c}\text { Povos indígenas } \\
\text { da América }\end{array}$} & $\begin{array}{l}\text { Povos da Antiguidade na África } \\
\text { (egípcios), no Oriente Médio } \\
\text { (mesopotâmicos) e nas Américas (pré- } \\
\text { colombianos). } \\
\text { Os povos indígenas originários do } \\
\text { atual território brasileiro e seus hábitos } \\
\text { culturais e sociais. }\end{array}$ & $\begin{array}{l}\text { (EF06HI08) Identificar os espaços territoriais } \\
\text { ocupados e os aportes culturais, científicos, sociais e } \\
\text { econômicos dos astecas, maias e incas e dos povos } \\
\text { indígenas de diversas regiões brasileiras. }\end{array}$ \\
\hline & $\begin{array}{l}\text { Conteúdos: Espaço e diversidade cultur } \\
\text { localização; A cidade de Tenochtitlán; I }\end{array}$ & $\begin{array}{l}\text { na América; O Império Asteca: conceito e } \\
\text { porte e saúde; O tlachtli; Características dos maias; As }\end{array}$ \\
\hline
\end{tabular}




\begin{tabular}{c|l|l}
\hline Capítulos & \multicolumn{1}{|c}{ Objetos de conhecimento } & \multicolumn{1}{c}{ Habilidades } \\
\hline & $\begin{array}{l}\text { cidades-Estado maias; Astronomia; Os incas; As cidades incas; O kipu; Indígenas das terras } \\
\text { onde hoje é o Brasil; Conhecendo os povos indígenas; Diferenças entre os indígenas; Troncos } \\
\text { linguísticos; As semelhanças entre os indígenas; Quéchua }\end{array}$ \\
\hline
\end{tabular}

Fonte: Elaborado a partir de Boulos, 2018, v.2.

Observando o quadro, percebemos que nesta unidade do livro do $6^{\circ}$ ano, edição 2018 , são trabalhadas com relação aos povos indígenas a habilidade: EF06HI08 - "Identificar os espaços territoriais ocupados e os aportes culturais, científicos, sociais e econômicos dos astecas, maias e incas e dos povos indígenas de diversas regiões brasileiras" (BRASIL, 2017, p. 417).

Adotando o mesmo critério, iniciamos com a determinação expressa da habilidade, quanto a do objeto de conhecimento está mais próxima do que expressa a Lei 11.645/08. O capítulo a ser primeiro analisado, portanto, é o capítulo 7 - Povos indígenas da América.

$\mathrm{Na}$ página de abertura três imagens atuais de povos indígenas de diferentes partes da América: Do Peru, uma tecelã inca expondo seus produtos; dos Estados Unidos, uma menina e um homem navajos em um festival de dança; do Brasil, uma menina guarani-mbya da Aldeia Kalipety, São Paulo - SP. As imagens e o pequeno texto levam o aluno a entender que os povos indígenas da América são diversos.

As primeiras informações são gerais quanto aos habitantes do continente antes da chegada de Colombo. Em seguida, os tópicos do capítulo fazem longa explanação sobre os astecas, os maias e os incas, até chegar nos - Indígenas das terras onde hoje é o Brasil. Nesse tópico também apresenta os números, antes da chegada de Cabral e os atuais, da população indígena no território brasileiro. Além disso, várias informações importantes quanto a diversidade cultural, a contribuição para os costumes brasileiros e para o português falado no Brasil, como estas do trecho a seguir:

\footnotetext{
Cada povo indígena possui uma cultura própria, isto é, língua, crenças e um jeito próprio de trabalhar, pensar, relacionar-se com a natureza e com os outros povos. As histórias e as culturas indígenas marcaram profundamente nosso jeito de ser, nossos hábitos, nossa língua etc. Por isso, é importante estudar suas contribuições para a história e a cultura brasileiras. Os indígenas estão presentes no dia a dia de todos os brasileiros; nos gestos, nos hábitos e no português falado no Brasil. Grande parte dos animais, vegetais e lugares do Brasil tem nomes indígenas de origem tupi (BOULOS, 2018, p. 119).
}

No tópico - Diferença entre os indígenas, o aluno é informado que entre esses povos há semelhanças e diferenças e que estas podem ser percebidas nos traços físicos e nas línguas que eles falam. Ao lado dos textos, três fotografias recentes: na primeira, um homem kamayurá; na segunda, uma mulher yanomami; na tecera, jovens pataxós. 
Depois das diferenças, um tópico para mostrar as - Semelhanças entre os indígenas. $\mathrm{O}$ autor apresenta que nas sociedades indígenas em geral, a posse da terra é coletiva, que a divisão do trabalho é feita por sexo e idade, e ainda especifica algumas tarefas para cada sexo.

Portanto, estes últimos tópicos do capítulo, tratando dos povos indígenas no Brasil, dá grande visibilidade a essas sociedades, traz textos com informações importantes, para combater o preconceito, e fotografias que levam ao interesse do aluno. No entanto, pela determinação da habilidade EF06HI08, o capítulo é dividido entre os demais povos pré-colombianos, incas, maias e astecas.

Observando a edição de 2015, o capítulo 5 é dedicado aos povos indígenas do Brasil. Embora o título seja - Os povos indígenas diferenças e semelhanças o capítulo também várias outras informações da temática em tópicos como: Povos indígenas no Brasil; conhecendo os povos indígenas; diferenças entre indígenas; as semelhanças entre os indígenas; a infância entre os indígenas; a adolescência; ser adulto, além toda a seção de atividades dedicada a temas indígenas do capítulo.

Importante observar que os demais povos indígenas da América, que foram abordados no livro do 6. ${ }^{\circ}$ ano na edição de 2018, são abordados no livro do 7. ${ }^{\circ}$ ano da coleção de 2015.

Dessa forma, em todos os momentos em que a temática indígena foi abordada no livro $6^{\circ}$ ano da coleção História Sociedade \& Cidadania, nas edições com as quais foi feito um paralelo, foi aqui apresentada. A conclusão é que na edição publicada antes da BNCC, os povos indígenas tiveram maior visibilidade.

\subsection{O Livro Didático de História do $7^{\circ}$ Ano - Volume 2}

Da mesma forma como foi feita a análise do livro do $6 .^{\circ}$ ano, no livro do $7 .^{\circ}$ ano partimos do quadro, presente no manual do professor da edição de 2018, que relaciona os objetos de conhecimento, e as habilidades correspondentes, determinados pela BNCC, com os capítulos. Assim, a sequência dos capítulos na análise fica determinada pela relação mais próxima com o que determina a Lei 11.645/08 em relação ao ensino da história e cultura dos povos indígenas. $\mathrm{Na}$ sequência, verificamos em qual capítulo, ou até mesmo em qual volume da edição de 2015 aquele conteúdo foi abordado, dando maior ou menor visibilidade aos indígenas, suas lutas, resistências e saberes.

Porém, é importante pontuar que mesmo que nos títulos dos capítulos, nos objetos de conhecimento e nas habilidades correspondentes, não seja evidenciada a abordagem referente aos 
indígenas, todos os capítulos nas duas edições foram lidos e verificado para identificar a presença dessa temática nos textos e/ou imagens.

Feita esta consideração, vamos aos objetos de conhecimento e habilidades do $7 .^{\circ}$ ano que mais evidenciam a temática que é o objeto da presente pesquisa. Iniciamos, portanto, com a habilidade que está mais próxima ao atendimento desse critério: EF07HI03 - "Identificar aspectos e processos específicos das sociedades africanas e americanas antes da chegada dos europeus, com destaque para as formas de organização social e o desenvolvimento de saberes e técnicas" (BRASIL, 2017, p. 419).

Essa habilidade é referente ao seguinte objeto de conhecimento da BNCC: Saberes dos povos africanos e pré-colombianos expressos na cultura material e imaterial. Assim sendo, o autor do livro analisado dividiu esse tema em dois capítulos: Povos indígenas: saberes e técnicas capítulo 1; e Povos e culturas africanas: malineses, bantos e iorubás.

Dessa forma, iniciamos nossa análise no livro do $7 .^{\circ}$ ano da coleção História Sociedade \& Cidadania $4^{\mathrm{a}}$ edição 2018, no capítulo 1 - Povos indígenas: saberes e técnicas. Neste, percebemos que mais uma vez a atenção maior foi dada aos maias, incas e astecas. Os povos indígenas do território brasileiro quase não têm visibilidade, apenas em um pequeno texto no final do capítulo, no tópico - Os tupis. Nesse tópico, apenas um pequeno trecho que apresenta uma informação que não está presente no livro do $6 .^{\circ}$ ano: “entre os grupos tupis que habitavam o litoral, estavam os tupinambás da área onde hoje é o Rio de Janeiro; e os tupiniquins que tinham suas aldeias onde hoje é Porto Seguro, na Bahia” (BOULOS, 2018, p. 17).

Neste capítulo o aluno do $7 .^{\circ}$ ano tem, portanto, no conteúdo do livro, quase uma revisão do que foi exposto no livro do $6 .^{\circ}$ ano sobre os povos pré-colombianos. Diferente da edição de 2015 que, conforme foi dito, o livro do 7. ${ }^{\circ}$ ano apresenta temas relacionados aos povos maias, incas e astecas, no capítulo 11 - “América: Astecas, maias e incas e tupis” (BOULOS, 2015, p.222). Porém, mais destaque é dado aos tupis que no capítulo do livro da edição de 2018.

No tópico dedicado a este povo indígena existente no Brasil - Os tupis - o autor inicia o texto informando ao aluno que entre os milhões de indivíduos que aqui havia antes da chegada de Cabral, agrupados em milhares de povos, boa parte destes falava a língua Tupi-guarani e que no litoral a presença mais forte era do povo tupi. Aponta a floresta amazônica como a provável origem do grupo e sua expansão nas terras desse país, iniciada por volta de 500 a. C., uns em direção ao interior, se estabelecendo no Sul, e outros rumo a foz do Rio Amazonas, seguindo depois pelo litoral no sentido norte sul (BOULOS, 2015). 
Ao lado de uma fotografia do ano de 2011 de crianças do povo tupi em um momento de lazer, a legenda traz a informação adicional que "os povos tupis dominavam desde Iguape, no litoral paulista, até a costa do Ceará; já os guaranis ocupavam desde Cananéia, no litoral paulista, até a Lagoa dos Patos, no extremo sul do país” e que no litoral também havia outros povos, como os aimorés e os Tremembés. Povos estes chamados pelos tupis de tapuias, palavra que significa inimigo na língua tupi (BOULOS, 2018, p. 238).

$\mathrm{Na}$ sequência, o texto principal aborda os costumes, os números de indivíduos em cada aldeia, a disposição das casas feitas de madeira em torno de um pátio central, usado para reuniões e festas. Cada casa, ainda na narrativa do autor, era habitada por uma família extensa, além de pai, mãe e filhos, moravam, também, avôs, sobrinhos, primos, netos e outros membros.

No tópico seguinte - Um modo próprio de governar - é apresentado a divisão de poder dos tupis. Que cada aldeia, tinha seu líder, o morubixaba, que ouvia as pessoas e considerava suas opiniões e pedia conselhos aos mais velhos quando havia decisões importantes. Outro representante nos povos tupis, presente no texto, é o pajé ou caraíba, nome dado ao líder religioso.

No tópico "indígenas do Brasil e suas contribuições", o aluno conhece algumas plantas alimentícias e medicinais, descobertas pelos povos indígenas e que atualmente beneficiam toda a humanidade. No boxe para saber mais, uma página inteira com um texto explicando o processamento da mandioca, técnica descoberta pelos indígenas, acompanhado de imagens.

Diante do exposto, neste capítulo do livro analisado na edição 2015, traz mais informações relevantes sobre a cultura e história dos povos indígenas brasileiros que o capítulo da edição de 2018. Houve, portanto, uma redução na visibilidade dada a esses grupos na edição publicada depois da BNCC. Nesta edição, conforme já observado, o destaque foi maior para os demais povos précolombianos, que foram subjugados pelos colonizadores espanhóis.

Voltando a tabela 2, temos mais três habilidades da BNCC para o 7. ano que estão relacionadas à temática indígena: EF07HI08 - "Descrever as formas de organização das sociedades americanas no tempo da conquista com vistas à compreensão dos mecanismos de alianças, confrontos e resistências" (BRASIL, 2017, p. 419); EF07HI09 - "Analisar os diferentes impactos da conquista europeia da América para as populações ameríndias e identificar as formas de resistência” (BRASIL, 2017, p. 419); e EF07HI10 - “Analisar, com base em documentos históricos, diferentes interpretações sobre as dinâmicas das sociedades americanas no período colonial" (BRASIL, 2017, p. 419).

De acordo com o quadro essas três habilidades são desenvolvidas no livro do $7 .^{\circ}$ ano, da edição de 2018, no capítulo 8 - Conquista e colonização espanhola da América. Já no capítulo 9 - 
América portuguesa: colonização, apenas a habilidade EF07HI10. Passemos ao que encontramos nesses dois capítulos. Em seguida, onde as temáticas dos dois são encontradas na edição de 2015 e como elas são apresentadas.

O capítulo 8 da edição de 2018, no título, conforme expresso no parágrafo anterior, usa o temo "conquista", para mostrar o processo de dominação espanhola aos povos indígenas da América, termo também usado no texto da BNCC quando determina as habilidades EF07HIO8 e EF07HI09. Portanto, esse capítulo, usando a expressão conquista, trata das invasões espanholas nas terras ocupadas, principalmente pelos maias, astecas e incas, além das atividades econômicas desenvolvidas e as formas de sociedade coloniais estabelecidas. Porém, também são abordadas as resistências desses povos indígenas americanos contra a invasão territorial e escravização sofrida.

No livro da coleção publicada antes da BNCC, ou seja, da edição de 2015, temos a mesma temática no capítulo 12. No título do capítulo temos, "Espanhóis e ingleses na América", portanto, não é utilizado o termo conquista, embora seja usado em tópicos no capítulo. Porém, de modo geral, nos textos, a representação desses povos é como a que está no capítulo da edição de 2018. Portanto, na comparação desses dois capítulos, não podemos afirmar que houve mudanças significativas da edição anterior a BNCC para a edição posterior.

O conteúdo do capítulo 9 - América portuguesa: colonização - da edição de 2018, que atende à habilidade EF07HI10, é encontrado na edição de 2015, no capítulo 13 - Colonização portuguesa: administração. Vamos, portanto às análises desses dois, suas semelhanças e diferenças.

Nas duas edições, temos o Tópico - O encontro, que descreve o estranhamento dos tupiniquins e dos portugueses, a surpresa diante das diferenças físicas e costumes entre esses dois povos. No entanto, percebemos que uma parte do texto presente na edição de 2015 não foi publicado na edição de 2018. Esse trecho encontrado na primeira afirma que "no contato entre os povos tupis e os portugueses, ocorreu tanto o relacionamento amistoso quanto a guerra", e que entre as relações amigáveis estão: o escambo, na troca de pau-brasil por objetos úteis aos indígenas; o casamento entre portugueses e mulheres tupis; e alianças, "com alguns grupos indígenas para guerrear contra outros, por exemplo, aos tupiniquins para guerrear contra os tupinambás, fazê-los prisioneiros e escravizá-los" (BOULOS, 2015, p. 275).

Com a retirada desse trecho na edição de 2018 há uma redução da visibilidade dos povos indígenas como sujeitos atuantes na história reduzindo seu protagonismo e contribuindo para que sejam vistos como personagens secundários. Outro ponto negativo nessa edição é a retirada do tópico “O desencontro", presente na edição de 2015. Nesse tópico temos o seguinte texto: 


\begin{abstract}
As armas de fogo empregadas pelos europeus nas guerras de conquistas causaram muitas mortes de indígenas, mas as doenças trazidas pelos europeus mataram mais do que as armas de fogo. Doenças como gripe, sarampo, tuberculose e varíola mataram em pouco tempo dezenas de milhares de indígenas; primeiro porque seus corpos não tinham defesas natural contra esses males. Segundo, porque, como ensinou Manuela Carneiro da Cunha, as doenças se manifestavam na forma de epidemia, atingido muitos índios da mesma aldeia de uma só vez; os doentes ficavam sem ter quem os socorresse ou alimentasse e morriam de fome ou sede. Houve ainda indígenas que morreram trabalhando como escravos ou resistindo à escravidão a que foram submetidos pelos europeus. Enfim, as doenças, as armas de fogo e o trabalho forçado causaram a elevada mortalidade entre os indígenas. Basta ver que, duzentos anos depois da chegada de Cabral, os Tupinambás já tinham sido varridos do litoral. Os sobreviventes fugiram para o sertão (BOULOS, 2015, p. 276).
\end{abstract}

A retirada desse texto, representa um silenciamento de fatos importantes para a compreensão da história dos povos indígenas brasileiros. Saber das epidemias trazidas pelos portugueses faz com que o aluno perceba que a resistência indígena não foi mais eficaz devido às armas biológicas que os colonizadores carregavam contra os indígenas, além das armas de fogo. Também é importante mostrar que a escravidão levava a trabalhos pesados que contribuíam para a mortalidade e que além das guerras, a fuga para o interior era uma forma de resistência, o que explica a ausência de grupos como os tupinambás do litoral, logo nos dois primeiros séculos da colonização.

O segundo tópico, que também foi eliminado da edição de 2018, apresenta a ordem dos Jesuítas que tinha como objetivo principal divulgar o catolicismo na Europa, América, África e Ásia, e que veio para o Brasil para converter os indígenas no período colonial. Presente na edição de 2015, uma parte do texto aborda a atividade destes religiosos na formação e catequese das crianças indígenas, e por meio delas buscar influenciar nos costumes dos adultos.

Outros tópicos do capítulo são semelhantes nas duas edições. Também comum às duas edições é um texto “A história do povo Tupinambá de Olivença que não está nos livros”, de autoria de Kaluanã Tupinambá. Em uma das edições, na seção para refletir, na outra, na seção atividades. Narra o autor indígena:

Há quinhentos anos atrás os portugueses invadiram nossas terras, deram o nome de Brasil a nosso território [...] e apelidaram os nativos como índios, achando que tinham chegado à Índia. [...] Hoje estamos exigindo nossos direitos, que sabemos que temos desde muito tempo, bem antes da invasão. [...] Agora os fazendeiros [...] falam que vivem nessa terra há 80 anos, mas eles esquecem que bem antes de Pedro Álvares Cabral invadir o Brasil, nós nativos [...] tupinambá, já habitávamos essas terras. Governo, fazendeiros e coronéis não falam dessa dívida que têm com o povo Tupinambá de Olivença. Lembremos que, em 1560, Mem de Sá ordenou que matassem todos os Tupinambá de Olivença, o que ficou conhecido na história como a Batalha dos Nadadores no Rio Cururupe, que significa rio dos sapos. Mas também ficou conhecido como rio de sangue, porque a água do rio ficou vermelha como sangue. Centenas de corpos dos guerreiros Tupinambá foram colocados enfileirados no meio da praia. [...] Mesmo com todo mal que [...] fazem contra nós, índios Tupinambá de Olivença, eles têm que saber que das árvores que eles derrubaram, ficaram muitas sementes e essas sementes brotaram e vêm brotando a cada dia que passa (BOULOS, 2015; 2018). 
É interessante mostrar esse texto porque permite uma reflexão sobre como a história do povo Tupinambá chega aos estudantes. Ao apresentar essa narrativa no livro didático, Boulos contribui para que a história que sempre foi mostrada pelo lado dos vencedores, agora chegue às escolas, contada pelos outros personagens, antes silenciados.

No livro do $7 .^{\circ}$ ano da edição de 2018, atendendo essa habilidade temos o capítulo12 - A formação do território da América portuguesa. Neste capítulo, no tópico - Os agentes da expansão territorial um subtópico sobre - Os bandeirantes e a caça ao "índio", afirma que "desde o início, os paulistas prenderam e escravizaram índios. A partir de 1620, [...] aumentou muito a procura por trabalhadores. Então os paulistas organizaram grandes bandeiras de caça ao índio. Para conseguir aprisionar muitos indígenas de uma só vez” (BOULOS, 2018, p.221).

Sobre a resistência indígena temos o seguinte texto:

Os indígenas, bem como os africanos, nunca aceitaram a escravidão pacificamente. Reagiam a ela de várias formas: suicídio, fugas para o interior e rebeliões. Depois da destruição das missões de Guairá, Itatim e Tape, por exemplo, os indígenas enfrentaram os bandeirantes, inclusive usando armas de fogo. Nessa luta venceram duas importantes batalhas: a de Caasapaguaçu, em 1638, e a de Mbororé, em 1641. Após essas derrotas, o bandeirismo de caça ao índio entrou em declínio (BOULOS, 2018, p. 221).

O autor, portanto, dá visibilidade à resistência indígena, inclusive apontando batalhas na quais os indígenas saíram vitoriosos. Assim, mais uma vez o protagonismo indígena ganha destaque, saindo um pouco do segundo plano na narrativa da expansão dos colonizadores nas terras que pertenciam esses povos.

No tópico - Os Jesuítas, o autor informa que nas missões criadas por esta ordem religiosa "os indígenas cultivavam cereais, frutas e erva-mate; extraíam da floresta cacau, baunilha, guaraná e plantas medicinais; produziam tecidos, mobílias e esculturas de madeira, etc.” (BOULOS, 2018, p. 224).

Ao discutir esse tópico em sala, cabe ao professor chamar a atenção do aluno para a forma de exploração do trabalho indígena pelos missionários. Afinal, conforme prossegue o texto, "vários desses produtos eram exportados para a Europa, com grande lucro”. “[...] embora, os indígenas aldeados tivessem [...] também um tempo reservado ao lazer e ao estudo" (BOULOS, 2018, p.224).

Encerramos aqui a avaliação do livro do 7..$^{\circ}$ ano da edição 2018 da coleção História, Sociedade \& Cidadania. De modo geral, podemos afirmar que os temas sobre os povos indígenas nele abordados, são encontrados com maior destaque na coleção publicada em 2015. 


\section{Considerações finais}

É incontestável a importância do livro didático e dos discursos nele contidos, para sua eficácia como instrumento no ensino de História na educação básica e sua relevância para o alcance da educação intercultural pretendida com essa política educacional. Por sua posição de destaque no contexto escolar, necessário se faz que se evite os riscos de se perpetuar um modelo de currículo hegemônico, o qual, podemos identificar na BNCC, defendido por grupos empresariais, o que pode trazer um retrocesso ou ser uma barreira a novos avanços na implantação da Lei n. 11.645/2008.

Pensar no alcance dos objetivos da Lei n. 11.645/2008 nos leva a refletir sobre os discursos nos livros didáticos, usados após sua promulgação, como parte importante de um processo que visa incluir, de forma significativa, o ensino da história e a cultura indígena na educação básica. E diante da implantação da BNCC, política educacional com influências de sujeitos defensores do pensamento hegemônico, eurocêntrico, colonizador, passamos a pensar como fica a temática indígena nessa nova proposta de currículo e, consequentemente, como fica a representação do indígena nos livros didáticos de história, o seja, os impactos da BNCC na implantação da Lei n. $11.645 / 2008$.

Esperamos que nossas reflexões neste artigo, possam ser um pontapé inicial, para que possamos aprofundar as questões inerentes a análise de livros didáticos de História, no contexto da Lei n. 11.645/08 e os possíveis impactos nos conteúdos sobre a temática indígena com a aprovação da BNCC e as adequações feitas pelas editoras de livros didáticos aos ditames da Base Nacional Comum Curricular, já em vigor desde o ano de 2018.

\section{Referências}

BOULOS JÚNIOR, Alfredo. História sociedade \& cidadania. $6^{\circ}$ ano. 3. ed. São Paulo: FTD, 2015.

BOULOS JÚNIOR, Alfredo. História sociedade \& cidadania. 6ª ano. 4. ed. São Paulo: FTD, 2018.

BOULOS JÚNIOR, Alfredo. História sociedade \& cidadania. $7^{\circ}$ ano. 3. ed. São Paulo: FTD, 2015.

BOULOS JÚNIOR, Alfredo. História sociedade \& cidadania. $7^{\circ}$ ano. 4. ed. São Paulo: FTD, 2018.

BRASIL. Lei no 9.394, de 20 de dezembro de 1996. Diário Oficial da União Lei de Diretrizes e Bases da Educação Nacional. Brasilia, 20 dez. 1996. Disponível em:

http://www.planalto.gov.br/ccivil_03/leis/19394.htm. Acesso em: 2 abr. 2021. 
BRASIL. Ministério da Educação. Base Nacional Comum Curricular. Brasília, 2018. Disponível em: http://basenacionalcomum.mec.gov.br/images/BNCC_EI_EF_110518_versaofinal_site.pdf. Acesso em 2 abr. 2021.

BRASIL. Ministério da Educação. Lei Federal n 10.639, de 09 de Janeiro de 2003. Altera a Lei n'. 9.394, de 20 de dezembro de 1996. Brasilia: MEC. 2005. Disponível em: https:/ /www2.camara.leg.br/legin/fed/lei/2003/lei-10639-9-janeiro-2003-493157-veto-13762pl.html. Acesso em: 2 abr. 2021.

BRASIL. Ministério da Educação. PNLD 2017: Guia de livros didáticos. História - ensino fundamental anos finais. Ministério da Educação - Secretaria de Educação Básica - Fundo Nacional de Desenvolvimento da Educação. Brasília: Ministério da Educação, Secretaria de Educação Básica, 2016. Disponível em: http://www.fnde.gov.br/component/k2/item/8813-guia-pnld-2017. Acesso em: 23 mar. 2021.

BRASIL. Ministério da Educação. PNLD 2020: Guia de livros didáticos. História - ensino fundamental anos finais. Ministério da Educação - Secretaria de Educaşão Básica - Fundo Nacional de Desenvolvimento da Educação. Brasília: Ministério da Educação, Secretaria de Educação Básica, 2019. Disponível em: https://www.fnde.gov.br/index.php/programas/programas-do-livro/pnld/guia-dopnld/item/13410-guia-pnld-2020. Acesso em: 23 mar. 2021.

BRASIL. Presidência da República. Lei ñ. 11.645, de 10 de Março de 2008. Disponível em: http://www.planalto.gov.br/ccivil_03/_ato2007-2010/2008/lei/111645.htm. Acesso em 2 abr. 2021.

CÁSSIO, Fernando Luis. Base Nacional Comum Curricular: ponto de saturação e retrocesso na educação. Revista Retratos da Escola, Brasilia, v. 12, n. 23, p. 239-253, jul./out. 2018. Disponível em: https://doi.org/10.22420/rde.v12i23.887. Acesso em: 17 mar. 2021.

NASCIMENTO, Jaciene Florentino do; SILVA, Janaína Guimarães da Fonseca e; ÁVILA, Virgínia Pereira da Silva de. O livro didático e a implementação da Lei. N. 10639/03 no ensino de história. Educação e Fronteiras, Dourados, v. 5, n. 13, maio 2016. Disponível em: https://ojs.ufgd.edu.br/index.php/educacao/article/view/5186. Acesso em: 17 mar. 2021.

QUIJANO, Aníbal. Colonialidade do poder, Eurocentrismo e América Latina. In: LANDER, Edgardo (org.). A Colonialidade do saber: Eurocentrismo e Ciências Sociais - Perspectivas latinoamericanas. Buenos Aires: CLACSO, 2005.

SILVA, Isaíde Bandeira da. MAGAGALHÃES DO Ó. Glauceane. PIMENTEL, Luciana Maria Fernandes. História e livro didático. In: MAGALHÃES JÚNIOR, Antônio Germano; ARAÚJO, Fátima Maria Leitão (org.). Ensino e Linguagem de História. Fortaleza: EDUECE, 2015.

SILVA, Isaíde Bandeira da. O livro didático de História no cotidiano escolar. Appris, 2014.

VEIGA, João Marcos. Base Nacional Comum: currículo para a educação básica em disputa. ANPED, 8 jul. 2015. Disponível em: https://anped.org.br/news/base-nacional-comumcurriculo-para-educacao-basica-em-disputa. Acesso em: 1 abr. 2015. 